\title{
Challenges of Autism Spectrum Disorders Families Towards Oral Health Care in Kingdom of Saudi Arabia
}

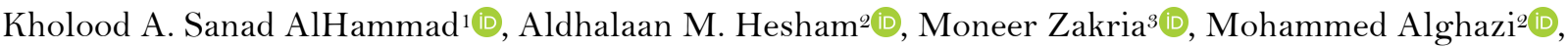

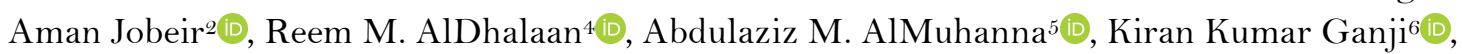 \\ Hezekiah Mosadomi(D)
}

\begin{abstract}
1'Dental Department, King Abdulaziz Airbase Armed Forces Hospital, Dhahran, Kingdom of Saudi Arabia. ${ }^{2}$ Centre for Autism Research, King Faisal Specialist Hospital and Research Centre, Riyadh, Kingdom of Saudi Arabia. ${ }^{3}$ Child Development Centre, Princess Noura Bent Abdul Rahman University, Riyadh, Kingdom of Saudi Arabia. ${ }^{4}$ Dental Department, Prince Mohammed Bin Abdulaziz Hospital, Riyadh, Kingdom of Saudi Arabia. ${ }^{5}$ Prince Sultan Military Medical City, Riyadh, Kingdom of Saudi Arabia.

${ }^{6}$ Department of Preventive Dentistry, College of Dentistry, Jouf University, Sakakah, Kingdom of Saudi Arabia. ${ }^{7}$ Research Centre, Riyadh Colleges of Dentistry and Pharmacy, Riyadh Elm University, Riyadh, Kingdom of Saudi Arabia.
\end{abstract}

Author to whom correspondence should be addressed: Dr. Kholood A. S. AlHammad, Dental Department, King Abdulaziz Airbase Armed Forces Hospital, Dhahran, Kingdom of Saudi Arabia. Phone: +966 545889900. E-mail: Kholoudalhammad@gmail.com.

Academic Editors: Alessandro Leite Cavalcanti and Wilton Wilney Nascimento Padilha

Received: 09 May 2019 / Accepted: 24 January 2020 / Published: 12 March 2020

How to cite this article: AlHammad KAS, Hesham AM, Zakria M, Alghazi M, Jobeir A, AlDhalaan RM, et al. Challenges of autism spectrum disorders families towards oral health care in Kingdom of Saudi Arabia. Pesqui Bras Odontopediatria Clín Integr. 2020; 20:e5178. https://doi.org/10.1590/pboci.2020.046

\begin{abstract}
Objective: To assess the knowledge, attitudes, and practice regarding oral health care among parents of autistic children and also the challenges faced by them in providing dental care for their Autism Spectrum Disorders (ASD) children's in four regions of Kingdom of Saudi Arabia. Material and Methods: In total, 263 parents of autistic children participated in this cross-sectional study who were enrolled from 4 major regions of Kingdom of Saudi Arabia. A self-administered questionnaire formulated in simple Arabic was distributed to parents of children diagnosed with autism or any form of ASD. The questionnaires consisted of demographic questions and also to assess their knowledge on oral health, child's oral hygiene practices and visits to their dentist, oral hygiene, experience and challenges in waiting room area before the dental treatment, acceptance of treatment or rejection, accessibility to find non-dental centers either government or private for treatment and their recommendations. Results: All the parents brushed their child's teeth using a toothbrush and fluoridated toothpaste. A total of $29.7 \%$ of the parents informed that their child never brushes teeth. A total of $41.4 \%$ of the parents visit the dental clinic when the child complains about dental problems and $54 \%$ find difficulty in locating appropriate dental clinic to deal with their ASD children. Most parents reported taking their child to a private office (38.8\%). Only $3.8 \%$ of parents reported that their children had seizures during dental procedures. Conclusion: The knowledge toward oral health was found to be inadequate among the majority of the parents. Parents of ASD children need to be educated about the consequences of oral health neglect and the importance of regular check-ups.
\end{abstract}

Keywords: Autism Spectrum Disorder; Child; Health Knowledge, Attitudes, Practice. 


\section{Introduction}

Autism spectrum disorder (ASD) refers to a group of neurodevelopmental disabilities with a core set of defining criteria that comprise impaired social interaction, communication, and restricted or repetitive behavioral stereotypes. Established features in the autistic child such as marked impairment in the use of multiple non-verbal communications, failure to develop social relationships and share experiences and interests, delay or complete lack of linguistic development, as well as inflexible adherence to rituals [1].

The prevalence of ASDs has risen significantly over the past decades; the ratio of affected males to females has remained between 3 and 4:1. Data from the Centers for Disease Control and Prevention's (CDC) 2009-2010 National Health Interview Survey (NHIS) estimate the prevalence based on parent report for children aged $3-17$ years at $1.1 \%[2]$.

Till date, literature doesn't reveal any specific number of diagnosed autistic cases, but a rough estimate of 18 per 10,000 was reported in 2009 [3]. Behavioral disturbances associated with ASD include self-injurious behavior, aggression, temper tantrums, psychiatric symptoms, and pica [4]. Impaired social interaction, communication, cognitive dysfunction and other associated psychiatric symptoms may impede dental care [5].

Patients with ASD may be incapable of cooperation in the dental setting as their developmental impairments may lead to great difficulties in interacting with other people and in understanding and following instructions. Dental care for such patients is neglected as they often face significant adversities in accessing dental care due to the difficulty of locating a dentist specialized in treating such individuals [6-8].

There is a lack of studies, which have elicited parental knowledge, attitudes, and practice (KAP) behaviors toward the oral health of children with ASD. Thus, the aim of this study was to assess the KAP regarding oral health care among parents of autistic children and also the challenges faced by them in providing dental care for their ASD children's in four regions of the Kingdom of Saudi Arabia.

\section{Material and Methods}

Study Design and Sample

A cross-sectional study was conducted using questionnaires in five major regions in the Kingdom of Saudi Arabia among parents of autistic children. All the children had been previously examined and diagnosed medically as ASD patients according to the Autistic centre's medical records. Randomized sampling technique was used to select the samples and a convenient sample of 263 was obtained.

\section{Data Collection}

A self-administered questionnaire in Arabic was distributed to the parents after checking its content and face validity. Initially, a pilot study was conducted on 20 parents with autistic children at Research of Autism Centre, King Faisal Specialist Hospital. Based on the response of the parents in the pilot study, the content validity process was done by three experts. Three domains of KAP questionnaire were assessed for content validity ratio (CVR), which was reported to be 0.950 for six examiners $(\mathrm{p}<0.05)$ with a significant difference for all items.

Prepared questionnaire included information to obtain demographic data such as name, age and gender of the child and parent and also to assess their knowledge on oral health, approach to dental care, oral hygiene, diet, preparation to dental visit, experience and challenges in waiting room area before the dental treatment, acceptance of treatment or rejection, accessibility to find non-dental centers either government or 
private for treatment and their recommendations. Adequacy of knowledge was considered optimum if positive response was obtained from more than 5 recipients.

Statistical Analysis

Data were tabulated with Statistical Package for Social Sciences (SPSS) software version 20.0 (IBM Corp., Armonk, NY, USA) and presented through descriptive statistics (absolute and percentage distributions).

Ethical Considerations

Ethical clearance for the present cross-sectional study was obtained from the Ethical Committee of Human Studies, REU Riyadh Elm University, College of Dentistry Research Centre vide reference number RAC*FRP2014/116. Consent was obtained from parents and every family was assured of the confidentiality of the collected data.

\section{Results}

All the parents brushed their child's teeth using a toothbrush and fluoridated toothpaste. A total of $29.7 \%$ of the parents informed that their child never brush teeth and $48.7 \%$ of the parents agreed that they use a toothpaste containing fluoride for brushing the teeth (Table 1). The daily intake of sugars, soft drinks and desserts was reported by $29.3 \%$ of the sample.

Table 1. Frequency of responses for oral hygiene practices and dietary habits.

\begin{tabular}{lcc}
\multicolumn{1}{c}{ Questions } & N & \% \\
\hline How many times does your child brush his/her teeth per day? & & \\
Once/day & 73 & 27.8 \\
Twice/day & 58 & 22.1 \\
Three times/day & 23 & 8.7 \\
Does not brush his/her teeth frequently & 31 & 11.8 \\
Never brushes his/her teeth & 78 & 29.7 \\
Does your child use toothpaste that contains fluoride? & 128 & \\
Yes & 66 & 25.7 \\
No & 69 & 26.2 \\
I don't know & & \\
The usual diet in terms of sugars, soft drinks, desserts of all kinds & 77 & 29.3 \\
Once per day & 44 & 16.7 \\
Once per week & 29 & 11.0 \\
A lot & 16 & 6.1 \\
Never & 97 & 36.9 \\
No response & & \\
\hline
\end{tabular}

Regarding the visit to the dentist, $63.1 \%$ had consulted the dentist previously. A total of $41.4 \%$ of the parents visit the dental clinic when the child complains about dental problems and $54 \%$ find difficulty in locating appropriate dental clinic to deal with their ASD children (Table 2). Most parents reported taking their child to a private office $(38.8 \%)$.

Regarding the preparation of children before the dental appointment, 20.5\% reported explaining to the child with visual support and $14.1 \%$ mentioned physical reinforcement. A percentage of $50.6 \%$ of parents reported difficulty in managing the child while waiting in dental clinic waiting room (Table 3 ). Only $3.8 \%$ of 
parents reported that their children had seizures during dental procedures. Sixty percent of parents were not aware of the adverse effects of child medications on oral health.

Table 2. Frequency of responses for dental visit and access to dental clinics.

\begin{tabular}{lcc}
\multicolumn{1}{c}{ Questions } & N & \% \\
\hline Has your child visited a dentist before? & 166 & 63.1 \\
Yes & 97 & 36.9 \\
No & & \\
How many times does your child visit the dentist? & 24 & 9.1 \\
Twice a year & 33 & 12.5 \\
Once a year & 109 & 41.4 \\
When the child complains & 97 & 36.9 \\
No response & & \\
Are there any difficulties finding an appropriate dental clinic/dentist & & \\
that can deal with your child case? & 142 & 54.0 \\
Yes & 24 & 9.1 \\
No & 97 & 36.9 \\
No response & & \\
Which Dental clinic do you take your child? & 41 & 15.6 \\
Governmental Clinic & 102 & 38.8 \\
Private Clinic & 23 & 8.7 \\
No Specific Clinic & 97 & 36.9 \\
No response & & \\
\hline
\end{tabular}

Table 3. Frequency of responses for preparing their child for dental therapy.

\begin{tabular}{lcc}
\multicolumn{1}{c}{ Questions } & N & \% \\
\hline How do you prepare your child before his dental visit appointment? & & \\
Physical Reinforcement & 37 & 14.1 \\
I do not prepare my child & 48 & 18.3 \\
No response & 27 & 10.3 \\
Explain to him with visual support & 54 & 20.5 \\
$\quad$ Verbal Encouragement & 97 & 36.9 \\
Do you have difficulties or challenges while you are waiting in the & & \\
dental clinic waiting room? & 133 & 50.6 \\
Yes & 33 & 12.5 \\
No & 97 & 36.9 \\
No response & & \\
Did your child ever have seizures during dental procedures? & 10 & 3.8 \\
Yes & 156 & 59.3 \\
No & 97 & 36.9 \\
No response & & \\
Did any dentist report to you that your child's medications affect oral & & \\
health treatment? & 8 & 3.0 \\
Yes & 158 & 60.1 \\
No & 97 & 36.9 \\
No response & & \\
\hline
\end{tabular}

A total of $32.7 \%$ reported that dentists refused to care for their sons / daughters (Table 4). A total of $35.8 \%$ of parents rated the dental treatment received by their child as Excellent / Good. The mean percentage of knowledge scores among these parents was $47.5 \%$. However, only $34.7 \%$ of them incorporated this knowledge in their daily practices. 
Table 4. Frequency of responses to rate the dentists co-operation in dental treatment.

\begin{tabular}{lcc}
\multicolumn{1}{c}{ Questions } & N & \% \\
\hline $\begin{array}{l}\text { Did any dentist refuse to treat your child because he has ASD, either } \\
\text { indirectly or directly? }\end{array}$ & \\
Yes & 86 & 32.7 \\
No & 80 & 30.4 \\
No response & 97 & 36.9 \\
How do you rate the dental treatment received to your child? & 21 & 8.0 \\
Excellent & 73 & 27.8 \\
Good & 28 & 10.6 \\
Acceptable & 44 & 16.7 \\
Unacceptable & 97 & 36.9 \\
No response & & \\
Does the medical insurance cover your ASD dental cost needs? & 36 & 13.7 \\
Yes & 130 & 49.4 \\
No & 97 & 36.9 \\
No response & & \\
\hline
\end{tabular}

\section{Discussion}

Since the last decade, ASD is considered as one of the major public health issues in many countries featured with static immature bone disorder and behaviour imbalance [9]. Thus parental cares with beliefs are vital considerations to improve their children's oral health. Hence parents are considered as key persons in an attempt to achieve the best oral health outcomes for autistic children.

Autistic children fail to develop joint attention; they also lack curiosity for the environment and inability to share information using spoken language, gestures and eye contact, which may obscure professional oral procedures. Impaired interpretation of stimulus intake may cause unusual responses to visual, olfactory, tactile, auditory, and gustatory signals [10,11].

Dislike to dental treatment, complications related with the medical condition, and trouble in locating a competent dentist was also stated by guardians of autistic children [12,13]. In the present study, similar findings were reported as parents reported that the inability to manage children during dental treatment and as well as in the waiting room of dental clinics. The difficulties in controlling and dentally treating children with ASD have been mentioned in a variety of studies $[4,10,14]$. In the present study, parents also reported that the preparation of a child during dental treatment is by reinforcement and not by willingness. Autistic children are challenging to the dental team attributable to inadequate attention span and a low frustration threshold, reduced communication skills [15]. To overcome such challenges behavior management-based analytical methodology is found to be effective in the examination and dental management of ASD individuals [16].

Dental management of autistic children is frequently a time-consuming process and necessitates numerous visits to start actual treatment [15]. In the present study, $60 \%$ of the parents were aware about the adverse effects of child medication on oral health of the child, yet $36 \%$ of the children had never visited a dentist. The reasons for not visiting a dentist were believed that their child lacked cooperative ability, and found the oral health services to be unaffordable. Some authors reported similar barriers for seeking dental care among children with special health care needs [17,18]. Similar findings of delaying first dental visits were reported by other studies conducted in the same area [19,20]. While the American Academy of Pediatric Dentistry calls for the first dental visit to be by one year of age, a large number of the participating parents 
believed dental visits should be an option only in the case of pain or dental problems as in accordance with the findings of the present study [21].

The use of toothbrushes and toothpaste was stated with the majority of the parents in this study and many other similar studies conducted in the same area [19,20]. Findings from the present study demonstrated that large number of parents didn't receive any dental information and didn't followed oral hygiene instructions as most of them brushed their children's teeth once a day and at the same time they didn't used brush for oral hygiene practice. This aspect of oral hygiene practise is considered largely inadequate on the parents path of ASD individuals taking into consideration of territorial outlook and privacy of ASD children $[1,10,11,22]$. Similar findings were reported by different authors suggesting only a fractional percentage of parents never brushed their children with disabilities living in the same area [10,20,23]. Hence, a collaborative initiative between psychiatrists and dentists emerges as a key factor in improving the quality and success in dental therapy of ASD children [18].

\section{Conclusion}

The knowledge toward oral health was found to be inadequate among the majority of the parents. Parents of ASD children need to be educated about the consequences of oral health neglect and the need for oral hygiene process with regular dental visits. Motivating parents with the importance of dental care and access to dental care with the affordability of health care services to a special group of ASD individuals are crucial factors for the establishment of optimal oral health in ASD individuals.

\section{Authors' Contributions}

\begin{tabular}{|c|c|c|}
\hline KASA & (iD) $0000-0001-9378-2766$ & Conceptualization, Investigation, Formal Analysis, Data Curation and Supervision. \\
\hline $\mathrm{AMH}$ & (iD) $0000-0001-7288-8588$ & $\begin{array}{l}\text { Conceptualization, Methodology, Formal Analysis, Data Curation and Writing - } \\
\text { Original Draft Preparation. }\end{array}$ \\
\hline MZ & (iD) $0000-0001-8483-4405$ & $\begin{array}{l}\text { Conceptualization, Methodology, Investigation, Formal Analysis, Data Curation } \\
\text { and Writing - Review and Editing. }\end{array}$ \\
\hline MA & (iD) $0000-0002-4806-6135$ & $\begin{array}{l}\text { Methodology, Formal Analysis, Data Curation, Writing - Original Draft } \\
\text { Preparation and Writing - Review and Editing. }\end{array}$ \\
\hline AJ & (iD) $0000-0002-5644-1572$ & Investigation, Formal Analysis, Data Curation and Writing - Review and Editing. \\
\hline RMA & (iD) $0000-0001-9908-7967$ & $\begin{array}{l}\text { Conceptualization, Methodology, Writing - Original Draft Preparation and } \\
\text { Writing - Review and Editing. }\end{array}$ \\
\hline AMA & (iD) $0000-0002-8270-1876$ & Investigation and Writing - Original Draft Preparation. \\
\hline KKG & (iD) $0000-0002-3178-9513$ & $\begin{array}{l}\text { Conceptualization, Methodology, Investigation, Formal Analysis, Data Curation, } \\
\text { Writing - Original Draft Preparation and Writing - Review and Editing. }\end{array}$ \\
\hline HM & $0000-0001-6190-6859$ & Investigation, Formal Analysis, Data Curation and Writing - Review and Editing. \\
\hline
\end{tabular}

\section{Financial Support}

None.

\section{Conflict of Interest}

The authors declare no conflicts of interest.

\section{References}

[1] Matia JI, Bissada NF, Maybury JE, Ricchetti P. Efficiency of scaling of the molar furcation area with and without surgical access. Int J Periodontics Restorative Dent 1986; 6(6):24-35. 
[2] Perou R, Bitsko RH, Blumberg SJ, Pastor P, Ghandour RM, Gfroerer JC, et al. Mental health surveillance among children-United States, 2005-2011. MMWR Surveill Summ 2013; 62(Suppl 2):1-35.

[3] Al-Salehi SM, Al-Hifthy EH, Ghaziuddin M. Autism in Saudi Arabia: presentation, clinical correlates and comorbidity. Transcult Psychiatry 2009; 46(2):340-7. https://doi.org/10.1177/1363461509105823

[4] Friedlander AH, Yagiela JA, Paterno VI, Mahler ME. The neuropathology, medical management and dental implications of autism. J Am Dent Assoc 2006; 137(11):1517-27. https://doi.org/10.14219/jada.archive.2006.0086

[5] Pilebro C, Bäckman B. Teaching oral hygiene to children with autism. Int J Paediatr Dent 2005; 15(1):1-9. https://doi.org/10.1111/j.1365-263X.2005.00589.x

[6] U.S. Department of Health and Human Services. National Institutes of Health. National Institute of Dental and Craniofacial Research. Practical Oral Care for People with Autism. Available from: https://www.nidcr.nih.gov/sites/default/files/2017-09/practical-oral-care-autism.pdf. [Accessed on December 14, 2018].

[7] DeMattei R, Cuvo A, Maurizio S. Oral assessment of children with an autism spectrum disorder. J Dent Hyg 2007; $81(3): 65$.

[8] Glassman P, Henderson T, Helgeson M, Niessen L, Demby N, Miller C, et al. Oral health for people with special needs: consensus statement on implications and recommendations for the dental profession. J Calif Dent Assoc 2005; 33(8):619-23.

[9] Faras H, Al Ateeqi N, Tidmarsh L. Autism spectrum disorders. Ann Saudi Med 2010; 30(4):295-300. https://doi.org/10.4103/0256-4947.65261

[10] Klein U, Nowak AJ. Characteristics of patients with autistic disorder (AD) presenting for dental treatment: a survey and chart review. Spec Care Dentist 1999; 19(5):200-7. https://doi.org/10.1111/j.1754-4505.1999.tbo1386.x

[11] Barbaresi WJ, Katusic SK, Voigt RG. Autism: a review of the state of the science for pediatric primary health care clinicians. Arch Pediatr Adolesc Med 2006; 160(1 1):1 167-75. https://doi.org/10.1001/archpedi.160.11.1167

[12] Altun C, Guven G, Yorbik O, Acikel C. Dental injuries in autistic patients. Pediatr Dent 2010; 32(4):343-6.

[13] Chandrashekhar S, Bommangoudar JS. Management of autistic patients in dental office: a clinical update. Int J Clin Pediatr Dent 2018; 1 1(3):219-27. https://doi.org/10.5005/jp-journals-10005-1515

[14] Marshall J, Sheller B, Williams BJ, Mancl L, Cowan C. Cooperation predictors for dental patients with autism. Pediatr Dent 2007; 29(5):369-76.

[15] Nelson LP, Getzin A, Graham D, Zhou J, Wagle EM, McQuiston J, et al. Unmet dental needs and barriers to care for children with significant special health care needs. Pediatr Dent 2011;33(1):29-36.

[16] Hidayatullah T, Agustiani H, Setiawan AS. Behavior management-based applied behaviour analysis within dental examination of children with autism spectrum disorder. Dental J 2018; 51(2):71-5. https://doi.org/10.20473/j.djmkg.v51.i2.p71-75

[17] Magoo J, Shetty AK, Chandra P, Anandkrishna L, Kamath PS, Iyengar U. Knowledge, attitude and practice towards oral health care among parents of autism spectrum disorder children. J Adv Clin Res Insights 2015; 2(2):82-6.

[18] Mangione F, Bdeoui F, Monnier-Da Costa A, Dursun E. Autistic patients: a retrospective study on their dental needs and the behavioural approach. Clin Oral Investig 2019. https://doi.org/10.1007/s00784-019-03023-7

[19] Wyne AH. Attitude of parents of disabled children towards dental visits in Riyadh, Saudi Arabia. Odontostomatol Trop 2007; 30(118):17-23.

[20] Al-Bader D, Al-Athel L, Wyne A, Chohan A. Oral health knowledge and sources of information in parents of Saudi disabled children. Pak Oral Dent J 2006; 26(1):101-8.

[21] American Academy of Pediatric Dentistry. Policy on Medically-Necessary Care. Latest Revision 2019. Available from: https://www.aapd.org/research/oral-health-policies--recommendations/policy-on-medically-necessary-care/. [Accessed on April 15, 2019].

[22] Bilgin H, Kucuk L. Raising an autistic child: perspectives from Turkish mothers. J Child Adolesc Psychiatr Nurs 2010; 23(2):92-9. https://doi.org/10.1111/j.1744-6171.2010.00228.x

[23] Al-Hussyeen A, Al-Sadhan S, Al-Dhalaan R, Al-Ghanim B. Pediatricians' knowledge and practices towards children's preventive oral health care in Saudi Arabia. Egypt Dent J 2003; 49:827-34. 